\title{
FLEXURAL PERFORMANCE EVALUATION OF VARIOUS CARBON FIBRE FABRIC REINFORCED GEOPOLYMER COMPOSITE
}

\author{
${ }^{\#}$ HIEP LE CHI, PETR LOUDA \\ Department of Material Science, Faculty of Mechanical Engineering, Technical University of Liberec, \\ Studenstká 2, 46117 Liberec, Czech Republic \\ ${ }^{\#}$ E-mail: lechihieptu109@gmail.com
}

Submitted October 16, 2019; accepted December 12, 2019

\begin{abstract}
Keywords: Geopolymer, Flexural strength, Compressive strength, High-strength geopolymer, TRG composite, Basalt fibre, Flexural toughness

In this paper, the results of an experimental investigation on the flexural behaviour, the mechanical properties, and the failure mode of a carbon textile reinforced geopolymer mortar composite subjected to four-point bending test are presented. The influence of various factors such as the type of the carbon fibre fabric, reinforcement ratio, dosage of the chopped basalt fibre on the flexural performance of the reinforced geopolymer composite is experimentally studied. The results reveal that the use of carbon fibre fabrics in the production of high-strength geopolymer matrix composites makes it possible for them to achieve a relatively high mechanical strength. Moreover, the value of the flexural strength and flexural toughness is strongly influenced by the reinforcement ratio and the mechanical properties of the fibre yarn of the carbon textile. The addition of the chopped basalt fibre $(B F)$ plays an important role in both the improved mechanical strength and the failure mode of the geopolymer textile composites. The failure mode of all the specimens shows either a pure bending failure or a peeling off the concrete at the matrix/fibre interface due to the rupture of some filaments in the outer layer and the loss of the bonding strength of the fibre yarn in the matrix leading to the slippage of the fibre yarns within the matrix.
\end{abstract}

\section{INTRODUCTION}

Currently, geopolymers which are made by reacting aluminosilicate materials with an alkali activator solution have become an interesting topic in research since they offer great potential for an alternative to Portland cement-based concrete $[1,2]$. It is well-known that Portland cement is a construction building material with admirable mechanical properties which are already proven. However, the Portland cement production process requires a high energy consumption and it involves a large amount of $\mathrm{CO}_{2}$ emissions. This binder is attributed to one of the major causes behind global warming $[3,4]$. The appearance of a geopolymer binder not only satisfies the mechanical properties, but also pays attention to a novel green building material over Portland cement in the case that there is a reasonable choice of raw materials for geopolymers $[5,6]$. The eco-compatibility of geopolymers, and other peculiarities, such as its high mechanical strength, acid resistance, seawater resistance, low shrinkage, thermal conductivity and fire resistance up to $1200{ }^{\circ} \mathrm{C}$ could be successfully achieved when the key factors, such as the raw materials, mixing ratio of the fillers, the amount and concentration and type of alkaline activator solution are properly selected.
Due to the increasing need for new materials to be produced with low energy consumption that offer sustainability, economy, feasibility, and particularly good mechanical properties, textile-reinforced concrete has attracted the consideration of many scientists over the past three decades. Composites resulting from a combination of multi-axial textile reinforcement and a fine-grained aggregate-based cementitious matrix, named textile reinforced concrete (TRC), bring the opportunity to repair/ strengthen old/new reinforced concrete structures. The use of TRC as an external strengthening system has gained popularity among other techniques. This is due to the favourable properties offered by TRC, such as its resistance to corrosion, its high strength to weight ratio, its ease and speed of application and the minimum change in geometry. Furthermore, TRC composites are also considered when manufacturing lightweight concrete structures or prefabricated sandwich panels with outstanding mechanical performance, and high-performance concrete construction with free-form designs [7-15]

A textile reinforced geopolymer (TRG) is a relatively new composite material. To date, many works have been performed to evaluate the effectiveness of the use of a textile reinforced geopolymer matrix composite for 
the external strengthening layer of existing structure members [16-24]. The reason for choosing geopolymer matrix composites is that they are more stable at elevated temperatures than a polymeric resin, while compared to a Portland cement matrix, they are better at anticorrosion in a chemical environment and have a lower $\mathrm{CO}_{2}$ footprint [25]. Despite many efforts in using the TRG composites as the strengthening layers for reinforced concrete, experimental investigations on the mechanical properties of the geopolymer matrix composite reinforced with carbon fibre fabrics is still limited in the current literature.

Due to the increasing interest in the area of composite materials made by geopolymer matrix and textile reinforcements, this paper is aimed at investigating the effectiveness of a carbon fabric geopolymer matrix composite in which the matrix is a geopolymer mortar containing various dosages of a chopped basalt fibre. A proven carbon textile with high mechanical properties combined with a high-strength geopolymer matrix promises that these composite materials can be used successfully in a wide range of applications where the TRC composite is required as mentioned above, such as the retrofitting of damaged structures, the strengthening of existing structures, the pre-casting of multi-layer proof panels or tunnel linings, etc. In the previous publication, the authors presented the flexural performance of basalt fibre meshes reinforced with a geopolymer matrix [26]. The results showed that the multi-layer and small net size type of the basalt fibre mesh should be used to reinforce the specimens in order to achieve a high reinforcement effectiveness. Besides, the geopolymer mortar matrix containing a high dosage of the $\mathrm{BF}$ has been addressed in the previous paper [27]. However, the use of a geopolymer mortar without the BF addition displayed a mechanical strength, which was still not as high as possible; this causes anxiety whether or not the $\mathrm{BF}$ addition has a positive effect on the failure mode of the TRG specimens. In the current work, the geopolymer mortars with a higher mechanical strength were used as a matrix to produce the TRG specimens. Carbon textiles are one of the most popular types of textile reinforcement for composites. When compared to basalt or glass textiles, they have been found to promote a better loadbearing capacity of the reinforced composite due to the high tensile strength and Young's modulus. Based on three types of carbon textile with respect to various net sizes, the aim of this paper is to evaluate the flexural performance of the composite thin-plates made with the high-strength geopolymer mortar in combination with carbon fibre meshes through the four-point bending test. Specimens of rectangular form with dimension of $400 \times 100 \times 15 \mathrm{~mm}^{3}$ were produced. The influence of some key factors such as the textile type, reinforcement ratio, dosage of the chopped basalt fibre was also studied.

\section{EXPERIMENTAL}

\section{Materials}

The geopolymer binder, supplied by Ceske Lupkove Zavody, a.s. Czech Republic, was used as the aluminosilicate source to produce the geopolymer mortar (in weight percent: $\mathrm{SiO}_{2}-47.4 ; \mathrm{Al}_{2} \mathrm{O}_{3}-29.7 ; \mathrm{CaO}-14.5$; $\mathrm{MgO}-2.6 ; \mathrm{TiO}_{2}-1.8 ; \mathrm{Fe}_{2} \mathrm{O}_{3}-0.5 ; \mathrm{K}_{2} \mathrm{O}-0.3 ; \mathrm{Na}_{2} \mathrm{O}-1$ ) along with a sodium silicate activator of modulus 1.73 (in weight percent: $\mathrm{SiO}_{2}-20.72 ; \mathrm{Na}_{2} \mathrm{O}-12.33 ; \mathrm{H}_{2} \mathrm{O}-$ - 66.68). A geopolymer cement was synthesised from calcined kaolin and shale clay residues in a rotary kiln (for $10 \mathrm{~h}$ at $750{ }^{\circ} \mathrm{C}$ ) with a $\mathrm{Si} / \mathrm{Al}$ molar ratio of 2.0.

Two different types of silica sand were used as the fine aggregate for the geopolymer mortar matrix (grain size: maximum of $0.063 \mathrm{~mm}$ and $0.6-1.25 \mathrm{~mm}$ ). An anticorrosive powder additive (microsilica) based on an amorphous $\mathrm{SiO}_{2}$ for concrete and the mortar was purchased from Kema Mikrosilika-Sanační centrum s.r.o., Sviadnov Czech Republic. The chemical composition of the microsilica was as follows (wt. \%): $\mathrm{SiO}_{2}-90, \mathrm{CaO}-0.8, \mathrm{MgO}-\max .1 .5, \mathrm{Al}_{2} \mathrm{O}_{3}-\max .1$, $\mathrm{Na}_{2} \mathrm{O}-0.5$. This additive was added into the geopolymer mortar to enhance both the workability of the fresh mortar and the mechanical strength of the hardened mortar. The chopped basalt fibre (BF) was provided by Kamenny Vek, and the tows were $6.4 \mathrm{~mm}$ long with individual fibre diameters of $13 \mu \mathrm{m}$, a density of $2.67 \mathrm{~g} \cdot \mathrm{cm}^{-3}$, the tensile strength was in the range of $2700-3200 \mathrm{MPa}$, and the tensile modulus was 85 - $95 \mathrm{GPa}$, shown in Figure 1.

Three types of the carbon fibre mesh corresponding to the net size were provided by Frisiverto s.r.o., Czech Republic, shown in Figure 1. The carbon fibre

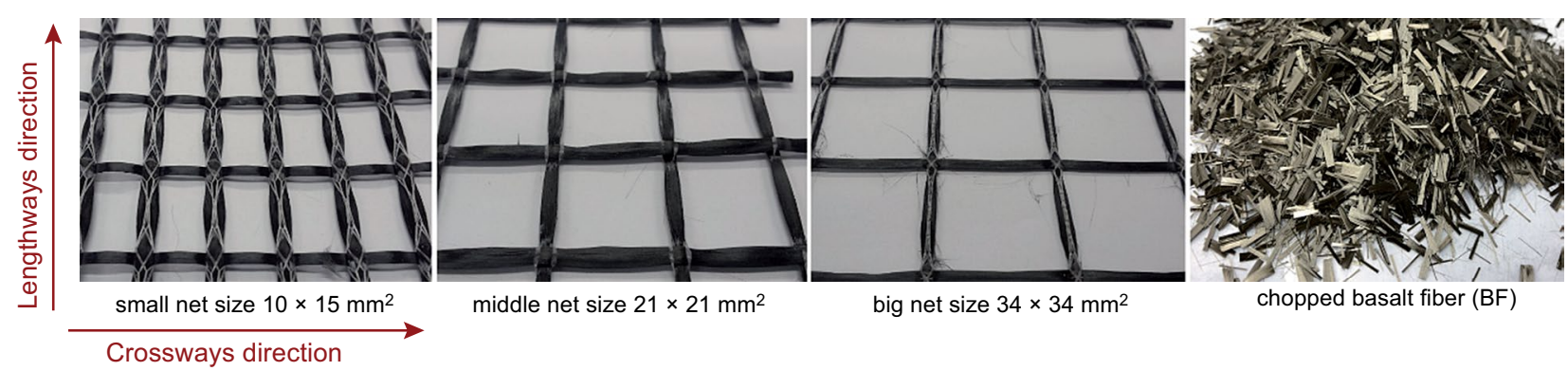

Figure 1. Images of the carbon fibre meshes and the chopped basalt fibre (BF). 
mesh with a small net size $(\mathrm{C}-10 \times 15)$ was made up of $48 \mathrm{~K}$ individual filaments for the yarns in the longitudinal direction and $12 \mathrm{~K}$ individual filaments for the yarns in the transverse direction, whereas the remaining two types (middle net size C- $21 \times 21$, big net size $\mathrm{C}-34 \times 34$ ) were made up of $48 \mathrm{~K}$ individual filaments for the yarns in both directions. The yarns of the carbon textile were arranged in two orthogonal directions $\left(0^{\circ} / 90^{\circ}\right)$ to form a textile mesh and they were coated using a sty-renebutadiene binder. Further detailed properties are shown in Table 1. In the four-point bending test of the geopolymer composite specimens, the carbon textiles were placed in moulds so that the force acting on the specimen was in the longitudinal direction of the fibre yarn.

\section{Geopolymer mortar preparation and} its mechanical properties

The raw materials and mixing ratio to produce the geopolymer mortar are shown in Table 2 . The geopolymer mortar was prepared by the following steps. Firstly, the geopolymer cement and the activator with the given ratio were mechanically stirred for about $4 \mathrm{~min}$ to gain a homogenous geopolymer paste. Secondly, fine particle reinforcements, including the silica fume and micro silica sand, were added to the slurry and the mixture was stirred for about 3 more min. Finally, the rough silica sand along with the chopped basalt fibre were added to the prepared mixture followed by mixing for a few minutes depending on the various BF dosage to ensure a homogenous mortar. It should be noted that due to the high content of the BF added into the mortar, in order to achieve the homogeneous mixture, the length of the BF must be changed, and it was chopped into smaller dimensions during the mixing. Thus, in this work, the original length of the BF does not affect the mechanical strength of the geopolymer mortar, but the fibre dosage does. Moreover, the mixing ratio of the particle reinforcements used in Table 2 was optimised in our lab. The freshly prepared mortar was poured into moulds with a dimension of $30 \times 30 \times 150 \mathrm{~mm}^{3}$ for the flexural and compressive tests. Three samples for each recipe were used for the flexural test and then the compressive strength was measured on both the residual pieces obtained from the flexural strength, which was conducted according to the EN 196-1 standard [28].

Table 1. The material characteristics of the carbon fibre meshes provided by the manufacturer.

\begin{tabular}{llll}
\hline Form & & Carbon fibre mesh & \\
\hline Fibre type & Carbon HTC 10/15-40 & Carbon HTC 21/21-40 & Carbon HTC 34/34-40 \\
\hline Fibre density & $1.77 \mathrm{~g} \cdot \mathrm{cm}^{-3}$ & $1.77 \mathrm{~cm}^{-3}$ & $1.77 \mathrm{~cm}^{-3}$ \\
\hline Number of threads (m) & 78 (lengthways); & 39 (lengthways); & 26 (lengthways); \\
\hline Weight & 55 (crossways) & 39 (lengthways); & 26 (lengthways); \\
\hline Tex & $350 \mathrm{~g} \cdot \mathrm{m}^{-2}$ & $330 \mathrm{~g} \cdot \mathrm{m}^{-2}$ & $212 \mathrm{~g} \cdot \mathrm{m}^{-2}$ \\
\hline \multirow{2}{*}{ Stitch spacing } & $3200 \mathrm{~g} \cdot \mathrm{km}^{-1}$ & $3200 \mathrm{~g} \cdot \mathrm{km}^{-1}$ & $3200 \mathrm{~g} \cdot \mathrm{km}^{-1}$ \\
\hline \multirow{2}{*}{ Tensile strength } & $10 \times 15 \mathrm{~mm}^{2}$ & $21 \times 21 \mathrm{~mm}^{2}$ & $34 \times 34 \mathrm{~mm}^{2}$ \\
\hline \multirow{2}{*}{ Young's modulus } & $($ centre to centre distance) & $($ centre to centre distance) & $($ centre to centre distance) \\
\hline \multirow{2}{*}{ Elongation } & $2551 \mathrm{~N} \cdot \mathrm{mm}^{-2}$ (lengthways); & $2531 \mathrm{~mm}$ (lengthways);) & $2544 \mathrm{~mm}^{-2}($ lengthways); \\
& $2847 \mathrm{~N} \cdot \mathrm{mm}^{-2}$ (crossways) & $2841 \mathrm{~N} \cdot \mathrm{mm}^{-2}$ (crossways) & $2720 \mathrm{~N} \cdot \mathrm{mm}^{-2}$ (crossways) \\
\hline
\end{tabular}

Table 2. The mixture of the geopolymer mortar matrix.

\begin{tabular}{cccccc}
\hline \multirow{2}{*}{$\begin{array}{c}\text { BF content } \\
\text { (wt. \% of geopolymer paste) }\end{array}$} & \multicolumn{5}{c}{ By weight ratio (-) } \\
\cline { 2 - 6 } & Geopolymer cement & Activator & Silica fume & Micro sand & Rough sand \\
\hline $0,2.5,5,7.5$ & 1 & 0.8 & 0.1 & 0.2 & 1.5 \\
\hline
\end{tabular}

Table 3. The mechanical properties of the geopolymer mortar matrix.

\begin{tabular}{|c|c|c|c|c|}
\hline \multirow{2}{*}{ Mortar type } & \multicolumn{2}{|c|}{ Flexural strength [MPa] } & \multicolumn{2}{|c|}{ Compressive strength [MPa] } \\
\hline & 7 days & 28 days & 7 days & 28 days \\
\hline Without BF & $9.46(0.35)$ & $11.78(0.48)$ & $60.84(2.34)$ & $78.56(3.32)$ \\
\hline $2.5 \% \mathrm{BF}$ & $10.87(0.49)$ & $13.34(0.55)$ & $70.08(3.75)$ & $92.37(2.27)$ \\
\hline $5 \% \mathrm{BF}$ & $11.80(0.98)$ & $14.72(1.17)$ & $78.85(3.73)$ & $98.87(2.84)$ \\
\hline $7.5 \% \mathrm{BF}$ & $12.77(0.59)$ & $14.92(0.58)$ & $78.89(4.48)$ & $98.99(3.39)$ \\
\hline
\end{tabular}


Table 3 represented the flexural strength and compressive strength of the geopolymer mortar at the age of 7 and 28 days. The results show that a geopolymer mortar with a reasonable choice of mixing ratio displayed a relatively high mechanical strength and its mechanical strength increases with an increase in the BF dosage. It should also be clearly stated that a BF dosage over $7.5 \%$ can be still worked in the geopolymer mortar, however, it takes more time to mix and cast and does not indicate that it significantly improves the mechanical strength.

\section{Manufacturing the carbon fibre fabric reinforced geopolymer composite}

For the four-point bending test, the samples are moulded in a rectangular form with dimensions of $400 \times 100 \times 15 \mathrm{~mm}^{3}$. Carbon fibre meshes were used as the reinforcement with the geopolymer mortar matrix, and the specimens were manufactured by the hand layup method. The layout of carbon textile in the mould is clearly shown in Figure 2. They were positioned in the mould with a desired distance by using thin metal plates at the ends of the mould. It should be said that three reinforcing layers were the possible number in order to ensure the easy penetration of the geopolymer mortar between the textile layers when the total thickness of the specimens was $15 \mathrm{~mm}$. For instance, the distance between two adjacent layers should be bigger than the size of the sand grains, so this distance was $2 \mathrm{~mm}$ in the case of the three reinforcing layers because the distance from the centre to the centre between the two adjacent layers was $4 \mathrm{~mm}$ while the self-thickness of the fibre yarn was about $2 \mathrm{~mm}$. The moulds were manually vibrated for a while in order to ensure the good penetration of the fresh mortar between the textile layers after being filled with the mortar and the textile. Figure 3 shows the manufacturing process of the TRG specimens. It should be clearly stated that the number of fibre yarns per one textile layer in the bearing direction and crossways direction is: 8 fibre yarns and 24 fibre yarns for the $\mathrm{C}-10 \times 15$ mesh, 4 fibre yarns and 15 fibre yarns for the $\mathrm{C}-21 \times 21$ mesh and 3 fibre yarns and 10 fibre yarns for the C-34×34 mesh, respectively. After casting, all the specimens were wrapped using a polypropylene film, and cured at room
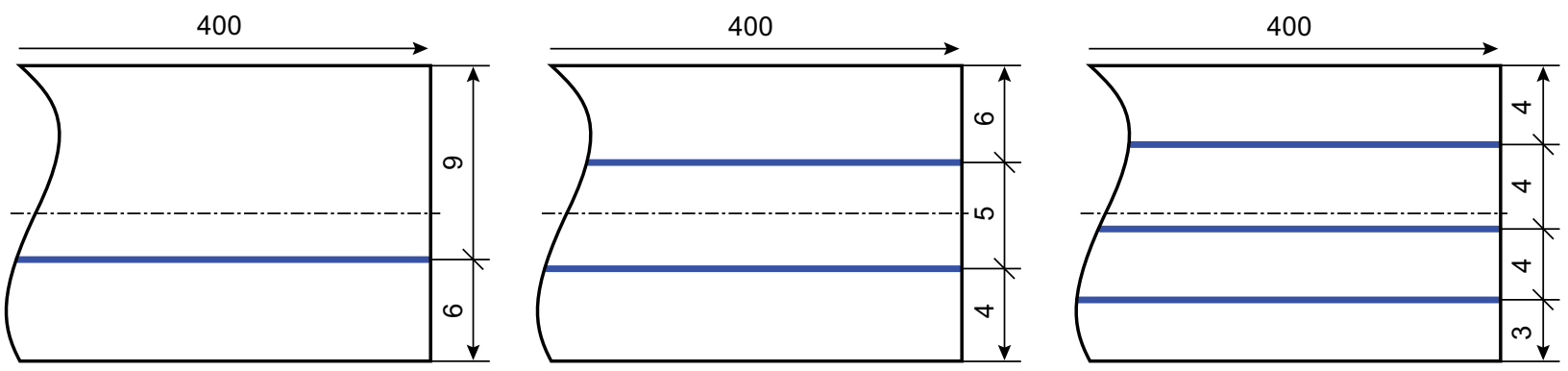

Figure 2. The layout of the carbon mesh layers in the TRG specimens.

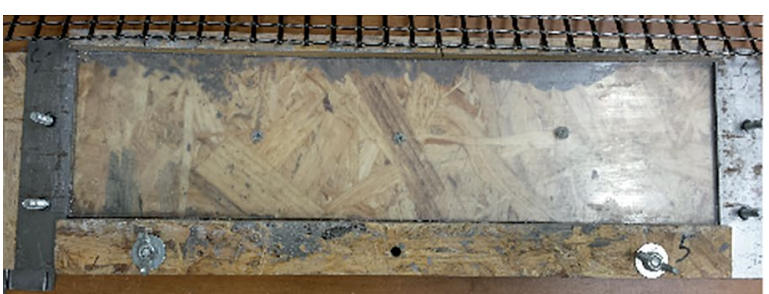

wood mould of $400 \times 100 \times 15 \mathrm{~mm}^{3}$

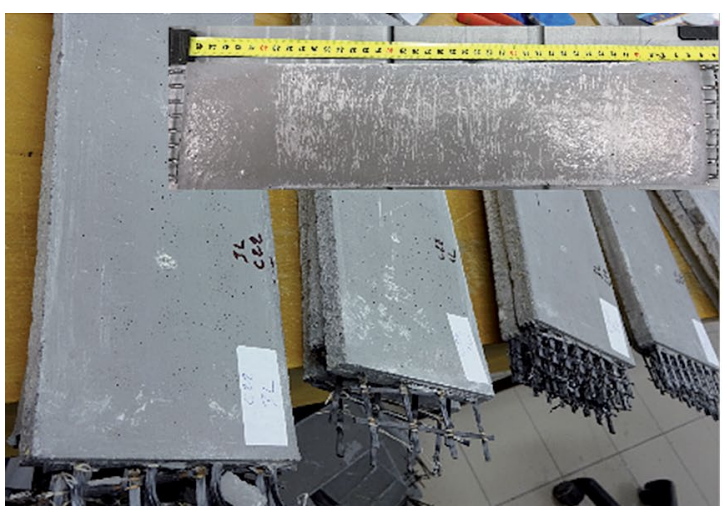

40 day specimens ready for test

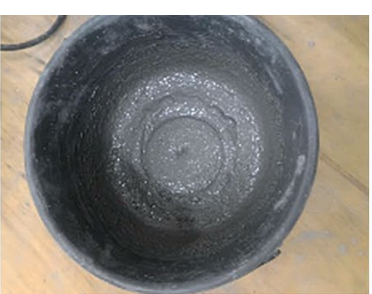

fresh prepared mortar

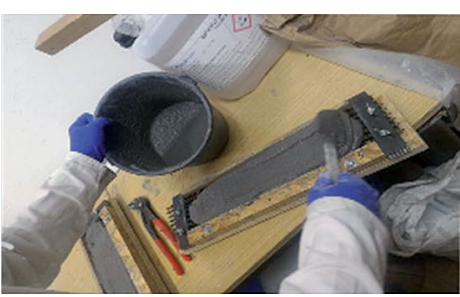

hand lay-up method
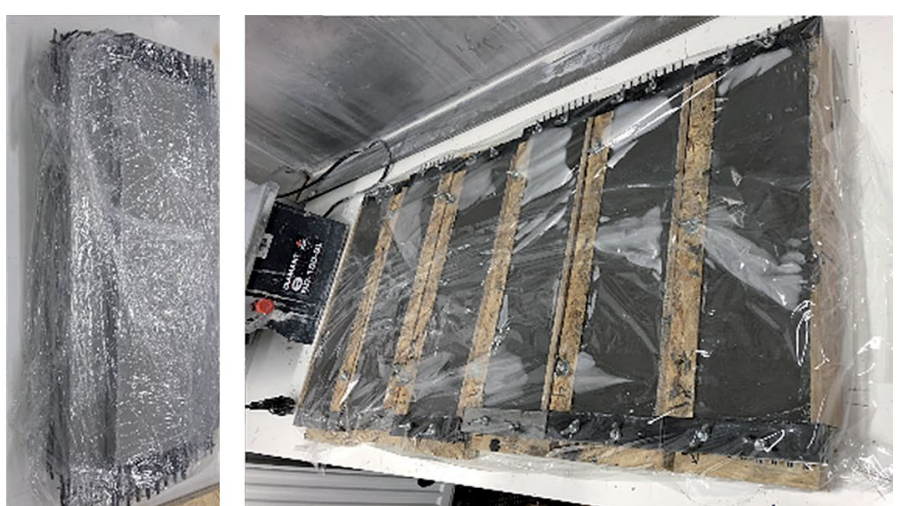

cover using a polypropylen film

Figure 3. The process of the geopolymer mortar reinforced with the carbon fibre mesh. 
temperature, $\sim 22{ }^{\circ} \mathrm{C}$, with $45 \%$ relative humidity for $24 \mathrm{~h}$. Afterward, the specimens were demoulded, and wrapped again using a polypropylene film, and kept at room temperature until testing.

In this work, the four-point flexural performance of the textile geopolymer composites was carried out based on a different number of textile layers, textile type and various dosages of the BF. In order to evaluate the effect of the number of textile layers and the textile type, a geopolymer mortar containing $5 \% \mathrm{BF}$ was used. One layer of $\mathrm{C}-10 \times 15$ textile was considered to investigate the influence of the BF dosage $(0 \%, 2.5 \%, 5 \%, 7.5 \%)$ on the flexural performance of the textile geopolymer composite. Three specimens for each mixture were prepared. A total of 36 specimens were tested at approximately 40 days after the casting.

The reinforcement ratio could be defined as the ratio of the area of the textile reinforcement to the area of the specimens. It can be expressed by the following Equation 1:

$$
\rho_{f}=\frac{A_{f}}{A_{c}}
$$

where $\rho_{f}$ is the reinforcement ratio, $A_{f}$ is the crosssectional area of the fibre yarn of the carbon textile in $\mathrm{mm}^{2}, \mathrm{~A}_{\mathrm{c}}$ is the cross-sectional area of the TRG specimens in $\mathrm{mm}^{2}$.

The cross-sectional area of the fibre yarn can be calculated by the following Equation 2:

$$
A_{f}=\frac{T e x}{D_{f}}
$$

where $D_{f}$ is the fibre density in $\mathrm{g} \cdot \mathrm{cm}^{-3}$, Tex is the linear density of the fibre yarn in $\mathrm{g} \cdot \mathrm{km}^{-1}$.

Thus, the TRG specimens that are reinforced with 1-3 layers of the carbon textiles will have a reinforcement ratio of $0.96 \%, 1.93 \%, 2.89 \%$ for the $\mathrm{C}-10 \times 15$ textile; $0.45 \%, 0.96 \%, 1.45 \%$ for the $\mathrm{C}-21 \times 21$ textile; $0.36 \%$, $0.72 \%, 1.08 \%$ for the $\mathrm{C}-34 \times 34$ textile, respectively.

\section{Test method}

A four-point bending test was used to evaluate the composite performance of the TRG specimens. The detailed description of the specimen arrangement and testing process was shown in the previous publication [26]. The testing machine with a load cell capacity of 100 kN (FP Lab Test II, from LABORTECH s.r.o Opava, Czech Republic), located at the Technical University of Liberec Laboratory, with an applied load under displacement control at a loading rate of $4 \mathrm{~mm} \cdot \mathrm{min}^{-1}$, was used. The four-point flexural strength in the special case where the outer support span is equal to three times the inner support span can be calculated as per Equation 3:

$$
\sigma=F l /\left(b h^{2}\right)
$$

where $\sigma$ is the four-point flexural strength in $\mathrm{MPa} ; F$ is the load at a given point on the load-displacement curve in $\mathrm{N} ; b$ is the width of the tested sample in $\mathrm{mm} ; h$ is the thickness of the sample in $\mathrm{mm} ; l$ is the support span in $\mathrm{mm}$.

\section{RESULTS AND DISCUSSION}

\section{Effect of the reinforcement ratio} and textile type

The influence of the textile type and the reinforcement ratio on the flexural behaviour of the composites is shown through means of the flexural loaddisplacement curves in Figures $4 \mathrm{a}-\mathrm{c}$, whereas the average values of the flexural strength, the flexural toughness, the ultimate displacement and a number of cracks are described in Figures 5a-d. In general, the geopolymer composite reinforced with the carbon fibre meshes produced a displacement-hardening behaviour and the load-displacement response of these specimens varies differently which depends on the mechanical properties of the fibre yarn and the reinforcement ratio. This type of behaviour is typically characterised by three different stages, which have been clearly presented in previous research $[26,29]$. The first stage is identified by a linear increase in the load until the first crack in the matrix happened. This stage is called an elasticlinear pre-cracking stage resulting from a combination of the geopolymer matrix and textile reinforcement. The second stage is a multiple-cracking phase as the proven oscillation of the curve when the applied load continues to increase, leading to the obvious pseudo-ductility behaviour of the composite. The rate of oscillation and slope of this phase depend strongly on the mechanical properties of the fibre yarn, reinforcement ratio, and mortar matrix. The number of cracks that each specimen will have is originated in this stage. The third stage is the post-cracking or crack-widening stage. In this stage,

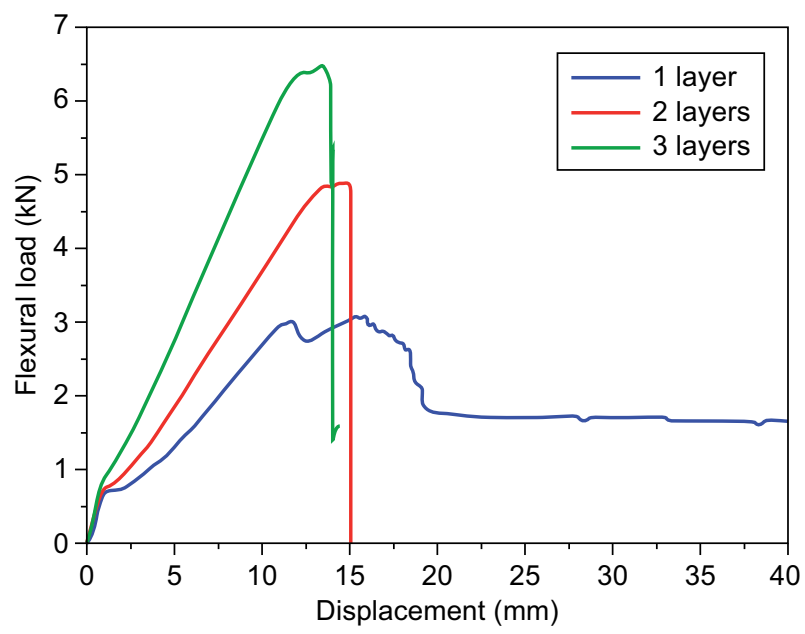

a)

Figure 4. The flexural load-displacement curves of the TRG specimens with respect to the textile type and reinforcement ratio: a) the $\mathrm{C}-10 \times 15$ composite. (Continue on next page) 


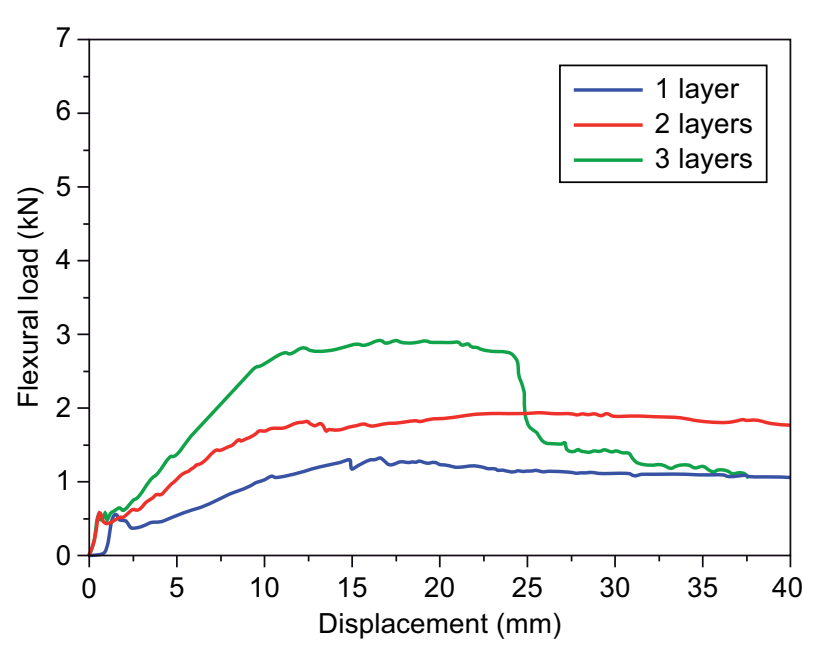

b)

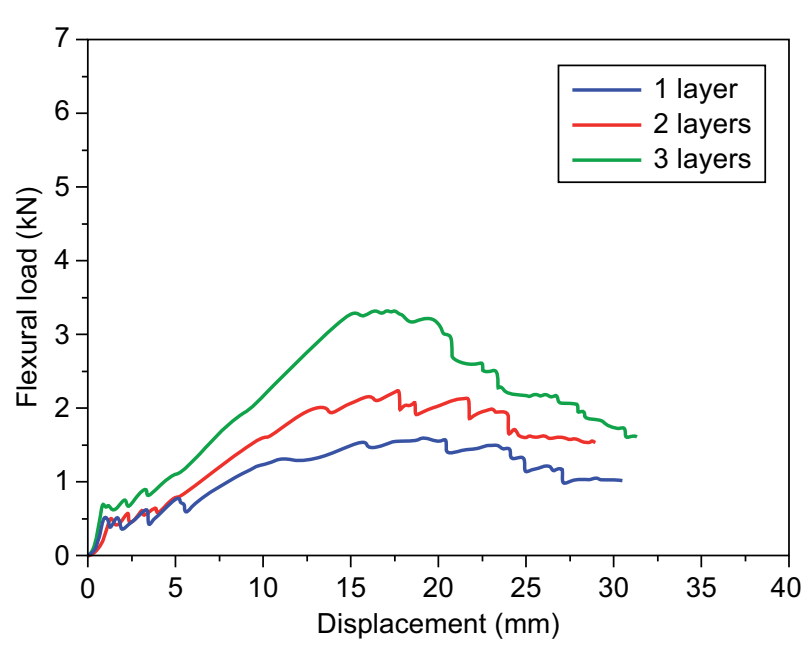

c)

Figure 4. The flexural load-displacement curves of the TRG specimens with respect to the textile type and reinforcement ratio: b) the $\mathrm{C}-21 \times 21$ composite; c) the $\mathrm{C}-34 \times 34$ composite.

the contribution of the geopolymer matrix is almost unaffected, the textile reinforcement governs the flexural behaviour of the composites. This stage ends once the load-bearing capacity of the composite cannot be carried out anymore through the ultimate load achieved.

The effect of the different layers of the C-10 $\times 15$ textile on the flexural performance of the composites over the flexural load-displacement curves is described in Figure 4a. For the one-layer reinforced specimens, the curve response with the three different stages was clear. After reaching the maximum load-bearing capacity, the specimens were broken down smoothly characterised by the gradual decrease of the curve in the load. When using two to three reinforcing layers, the stiffness of the TRG specimens improved significantly as seen through the absence of stage 2 and the higher slope of stage 3 . Using a high reinforcement ratio is one of the factors causing the absence of stage 2 which was mentioned in the previous literature [30]. The ending of stage 3 is marked by a sudden drop in the load almost to zero along with a loud noise. This was found out to be that the $\mathrm{C}-10 \times 15$ composites with the higher reinforcement ratio lead to more catastrophic brittle failure. The reason of this is that the amount of energy that the specimens absorb will be released just as much as when the specimens are destroyed; thus, the greater the amount of the accumulative energy, the more catastrophic failure of the specimens is. In this case, it can be concluded that the stiffness of the composites was governed by the stiffness of the geopolymer matrix, the material characteristic of the fibre yarn, and the reinforcement ratio. It was found that the absence of stage 2 results in the maximum flexural strength and stiffness. Similar to the C-10 $\times 15$ composites, the positive effect of the different layers of the two remaining types of carbon textiles on the flexural behaviour of the TRG specimens can generally be seen in Figures 4b-c. With the increasing reinforcement ratio, the TRG specimens obviously have a higher loadbearing capacity. In other words, it should be noted that by comparing the development of stage 1 between tested specimens, the slope of first stage of the curve is nearly the same for all tested TRG specimens, but the first-crack load value does not follow a logical rule. This phenomenon is attributed to the presence of the textile reinforcement in the matrix. The stiffness and the value of first-crack load in this stage are predominantly governed by the stiffness of the matrix. However preexisting micro-cracks, especially at the matrix/fibre interface, which can be formed during manufacturing, curing, and setting-up of the specimens, also contribute to the reduction in the first-crack load. The higher the reinforcement ratio, the greater the probability of the presence of more micro-cracks in the matrix is. On the other hand, by comparing the flexural behaviour between the $\mathrm{C}-21 \times 21$ composites and the $\mathrm{C}-34 \times 34$ composites, it was found that the mechanical properties of the fibre yarn have a strong effect on the response of the flexural loaddisplacement curves which leads to the interesting results of the mechanical properties of the TRG composites (Figure 5). As mentioned in Table 1, although the tensile strength of the fibre yarns has similar values (only considering the fibre yarns in the lengthways direction - the load-bearing direction), the fibre yarns of the $\mathrm{C}-21 \times 21$ textile show a lower Young's modulus and higher elongation than those of the $\mathrm{C}-34 \times 34$ textile; thus, as a result, the $\mathrm{C}-21 \times 21$ composites will tend to exbibit a more pseudo-ductile behaviour in bending, compared to those reinforced with the $\mathrm{C}-34 \times 34$ textile, as proven by the lower slope and less oscillation in stage 2 . In addition, in stage 3 , just before and just after reaching the maximum load-bearing capacity, the $\mathrm{C}-21 \times 21 \mathrm{com}-$ posites almost maintain the unchanged load-bearing capacity with an increasing displacement (Figure 4b). 
The effect of the reinforcement ratio and the textile type on the flexural strength, the flexural toughness, the displacement and the crack number of the TRG specimens is presented in Figures 5a-d. It should be noted that due to using the geopolymer matrix with the same recipe for all the tested specimens, the different comparison of the first-crack strength between the tested specimens is not mentioned, and the difference in the first-crack strength observed between the tested specimens was discussed above. In general, the mechanical strength improved significantly with the increasing reinforcement ratio. The superiority of the reinforcement ratio in the $\mathrm{C}-10 \times 15$ composites makes them achieve a remarkably higher flexural strength, compared to those reinforced with the $\mathrm{C}-21 \times 21$ textile and the $\mathrm{C}-34 \times 34$ textile (Figure $5 \mathrm{a}$ ). Even the composites reinforced with three layers of the $\mathrm{C}-21 \times 21$ and $\mathrm{C}-34 \times 34$ textiles have almost the similar flexural strength achieved by the $\mathrm{C}-10 \times 15$ composites reinforced with one-layer only. When comparing the flexural strength between the $\mathrm{C}-21 \times 21$ composites and the $\mathrm{C}-34 \times 34$ composites, the mechanical properties (Young's modulus and elongation) of the fibre yarn have a significant influence on the composite strength. Although the $\mathrm{C}-21 \times 21$ composites apparently have a higher reinforcement ratio than the $\mathrm{C}-34 \times 34$ composite (considering the same reinforcing layer), they could not produce a higher value in the flexural strength. For the $\mathrm{C}-10 \times 15$ textile, the specimens reinforced with two and three layers increased in the flexural strength by $58.42 \% \mathrm{MPa}, 113.83 \% \mathrm{MPa}$, respectively, compared to the one-layer reinforced specimens. For the C-21×21 textile and the $\mathrm{C}-34 \times 34$ textile, the specimens reinforced with two and three layers increased in the ultimate flexural strength by $38.79 \%, 45.12 \%$ and $117.73 \%$, $102.62 \%$, respectively. Figure $5 \mathrm{~b}$ shows the results of the flexural toughness of the TRG specimens. The flexural toughness, the so-called absorption energy capacity, is defined as the resistance of a material to failure or crack propagation. Toughness implies the amount of energy the specimen is able to absorb under loading up to a

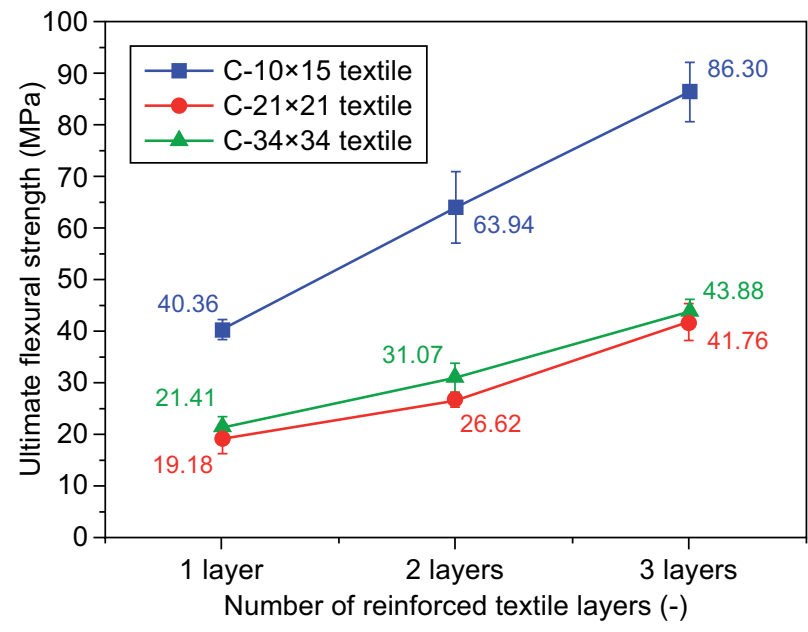

a)

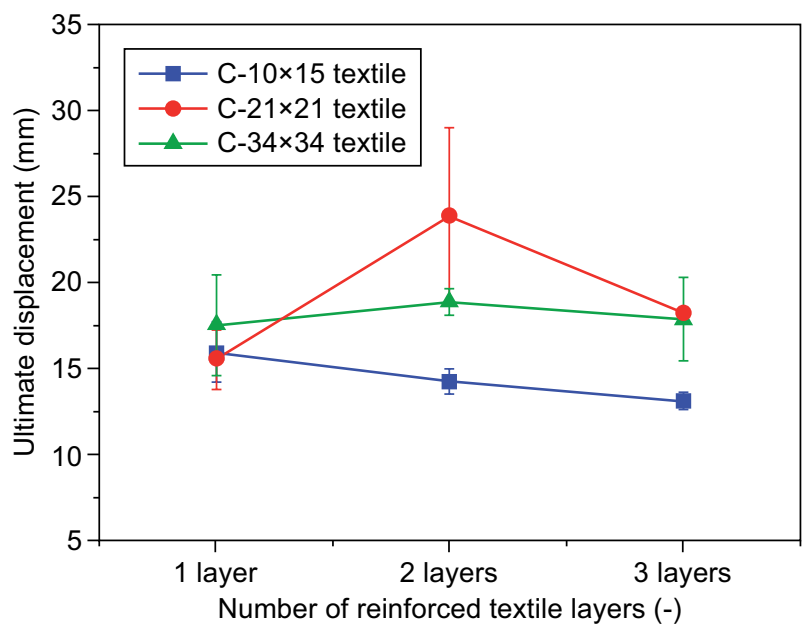

c)

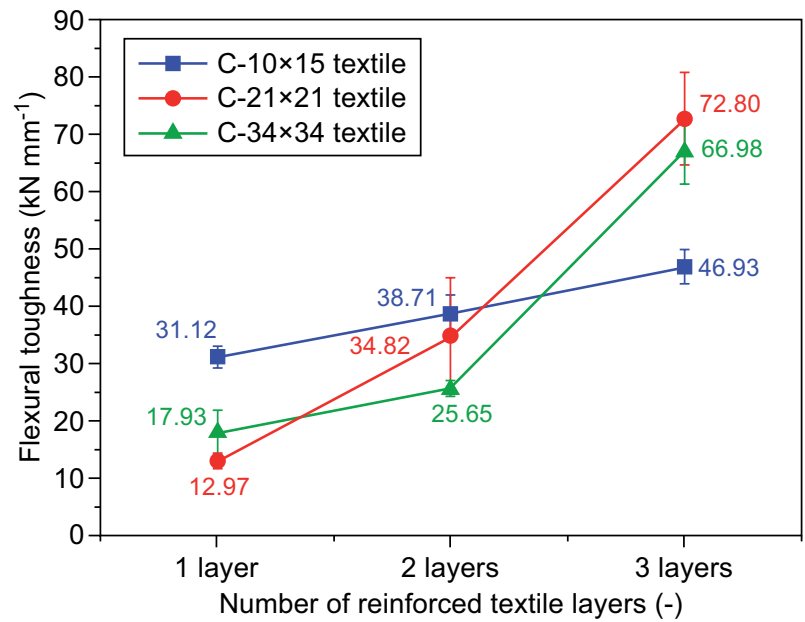

b)

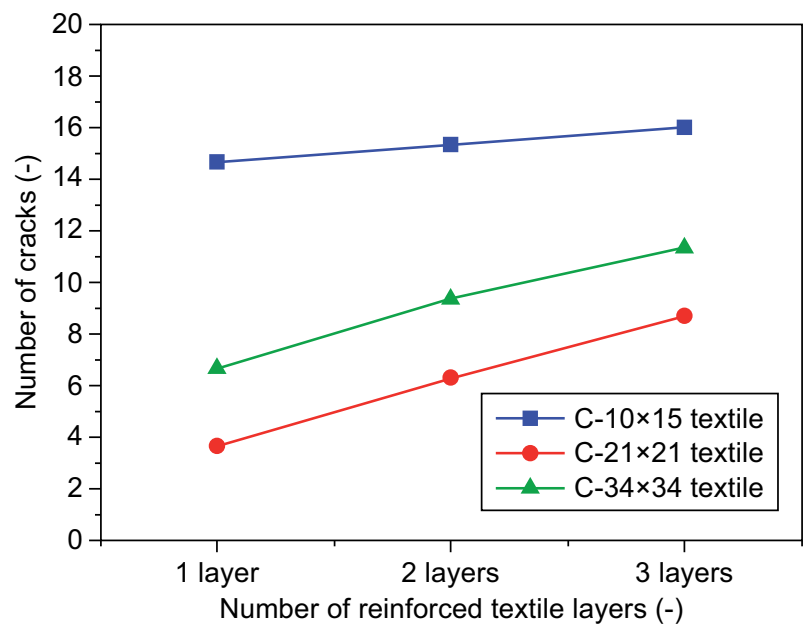

d)

Figure 5. The experimental results of the TRG composites with respect to the textile type and the different number of textile layers: a) the ultimate flexural strength; b) the flexural toughness; c) the ultimate displacement; d) the number of cracks. 
specified displacement, which is clearly described in the ASTM/C 1609 Standard. In this work, it is measured as the area under the respective load-displacement curves up to the peak load (ultimate load). It was observed that when the specimens reinforced with three layers of the textile are considered, the $\mathrm{C}-21 \times 21$ composites show the highest value of the flexural toughness (Figure $5 \mathrm{~b}$ ). It can be explained by fact that the high elongation of the $\mathrm{C}-21 \times 21$ textile positively affected the TRG composite ductility (Figure $5 \mathrm{c}$ ), which compensates for the low flexural strength; as a result, the flexural toughness was improved. This reveals that using both a reasonable reinforcement ratio and textile type make the composites possible to significantly enhance the flexural toughness. Figure $5 \mathrm{~d}$ shows that the number of the cracks increased with the increasing number of the textile layers. Based on this result, we also see that the stiffness of the composites is related to the number of cracks. The composites with the higher stiffness will delay the propagation of the cracks longer, which results in the reduction in the crack width and an increase in the number of the cracks at the tension edge.

The flexural failure modes of the TRG composites are displayed in Figure 6. It was observed that the TRG specimens could exhibit two different types of bending failure: i) a loss of the bonding strength at the matrix/fibre interface along with a partial rupture of the filaments at the outer layer leads to the slippage of the fibre yarns within the mortar matrix resulting in a pure flexural failure, ii) the initiation of the failure process is the same like the type 1 failure mode, then as soon as the TRG specimens reach their maximum load-bearing capacity, a sudden debonding process and a catastrophic collapse occurs almost simultaneously with loud noises. As seen in Figure 6, almost all of the TRG specimens have the same type 1 failure mode, while those reinforced with 2-3 layers of the $\mathrm{C}-10 \times 15$ textile have the type 2 failure mode.
Effect of the chopped basalt fibres

The effect of the dosage of the chopped basalt fibres on the flexural behaviour of the TRG specimens reinforced with one layer of the $\mathrm{C}-10 \times 15$ textile is described through means of the flexural load-displacement curves in Figure 7, whereas Figure 8a-b show the mean values of the flexural strength, the flexural toughness, and the number of cracks of the corresponding specimens. It can be seen that the mortar matrix with the BF addition significantly improved the mechanical properties of the TRG composites. The positive effects of increasing $\mathrm{BF}$ dosage on the load-displacement responses of the composites can be clearly seen through a higher first-crack load, higher maximum bearing capacity, less fluctuation in stage 2 and higher stiffness, compared to those without the BF addition (Figure 7). The improvement in the mechanical

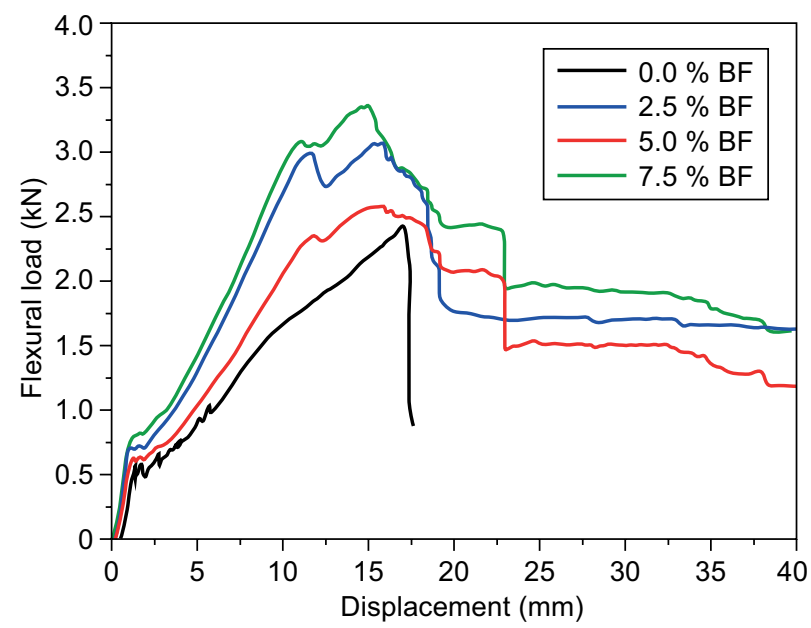

Figure 7. The response of the flexural load-displacement curves of the one textile layer reinforced specimens without and with the chopped basalt fibres.

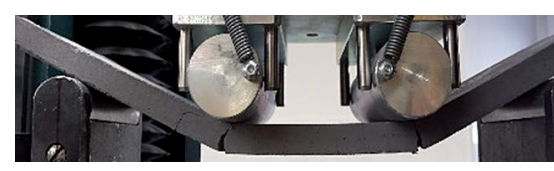

C-10×15- 1 layer

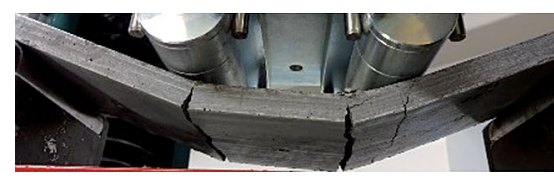

C-21×21 - 1 layer

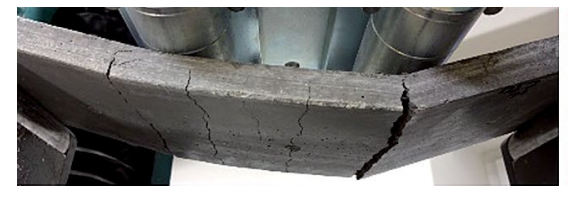

C-34×34 - 1 layer

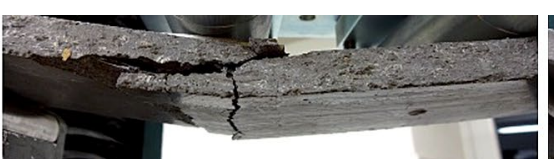

C-10×15 - 2 layers

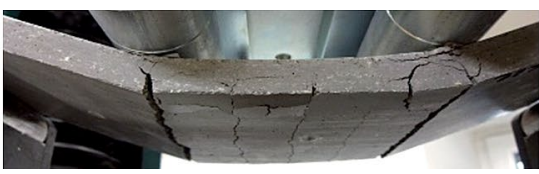

C- $21 \times 21-2$ layers

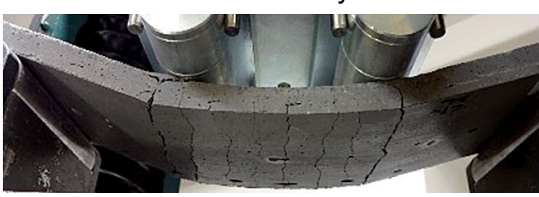

C-34×34 - 2 layers

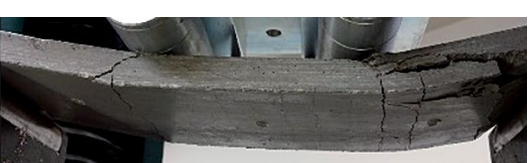

C-10×15 - 3 layers

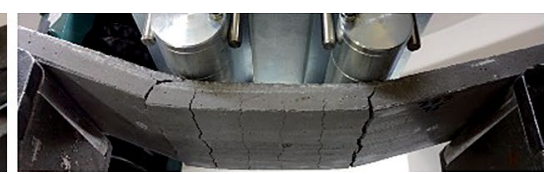

C-21×21 - 3 layers

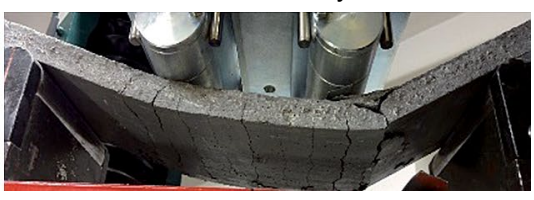

C- $34 \times 34-3$ layers

Figure 6 . The failure modes of the TRG specimens corresponding to the textile type and a different number of textile layers. 
properties of the textile-reinforced composite resulting from the BF addition could be explained as follows: i) the randomly distributed fibres in the matrix will help to reduce the overall shrinkage strains, thus decreasing the internal flaws in the matrix. On the other hand, if they do occur, the fibres could reduce their development which induces the formation of micro-cracks [31]; ii) due to the bridge effect of the chopped fibre at the micro-cracks, the mortar matrix has higher mechanical properties since the

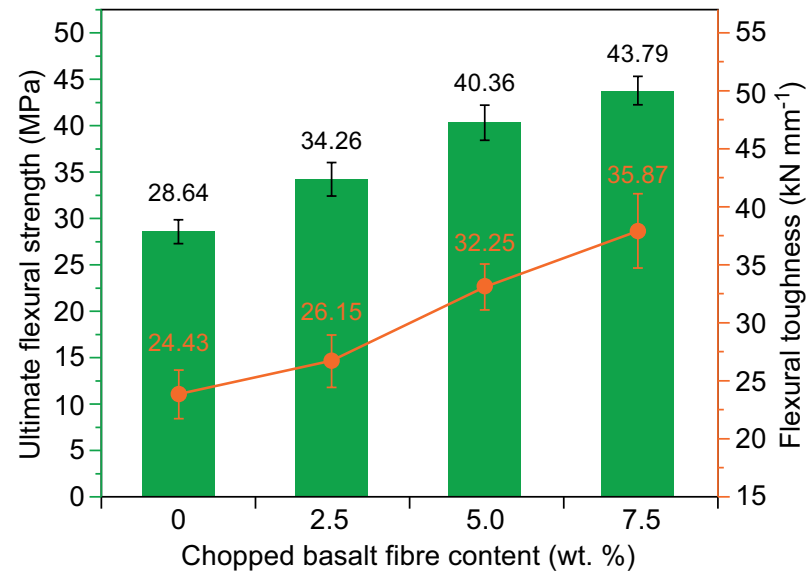

a)

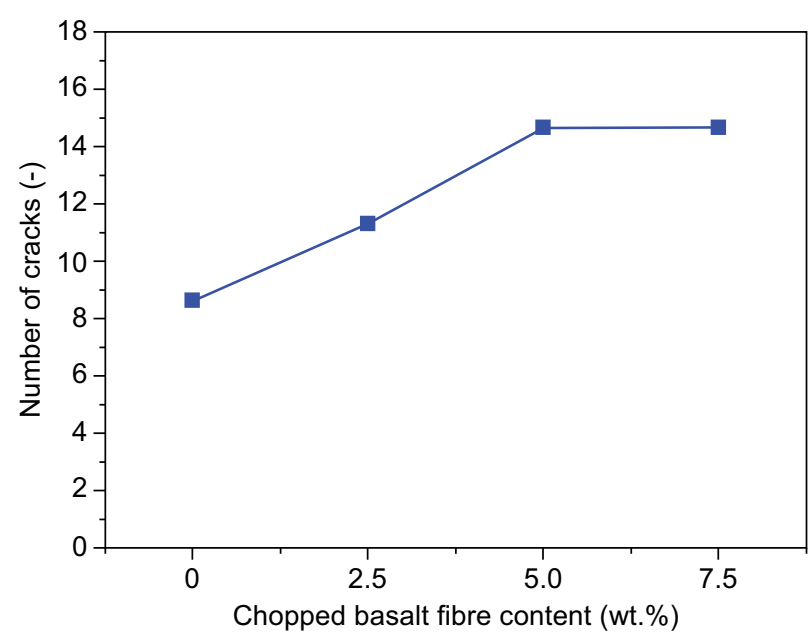

b)

Figure 8. The experimental results of the one textile layer reinforced specimens without and with the chopped basalt fibres: a) the flexural strength and flexural toughness; b) the number of cracks at the peak load.

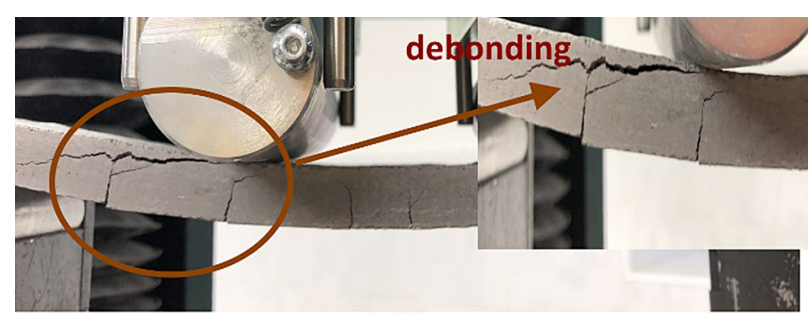

without addition of choped basalt fibre shift from micro-cracks to macro-cracks demands higher stress. Moreover, the connection between the fibre yarns of the textile and the geopolymer mortar is also promoted due to this bridging effect. In this case, it could be said that the chopped fibre contributes to enhancing the efficiency of the textile in the reinforcement as well. The TRG composites with the BF addition confirm the high-quality advancement in the aspect of the bending strength and, the higher the fibre dosage, the higher the bending strength when compared to the composites without the BF addition. The average ultimate flexural strength of the TRG specimens without the BF addition is $28.64 \mathrm{MPa}$. The average ultimate flexural strength of the TRG specimens with the BF addition of $2.5 \%, 5 \%$, and 7.5 increases by approximately $19.62 \%, 40.92 \%$, and $52.89 \%$, respectively, compared to those without the $\mathrm{BF}$ addition. The specimens also increase in the flexural toughness with the increasing BF content. The average flexural toughness of the specimens without the BF addition is $21.03 \mathrm{kN} \cdot \mathrm{mm}$. The average flexural toughness of the specimens with the BF addition of $2.5 \%, 5 \%$, and $7.5 \%$, increases by $7.04 \%, 32.00 \%$, and $46.83 \%$, respectively, compared to those without the BF addition. In addition to improving the mechanical properties, the $\mathrm{BF}$ addition also clearly impacts the failure mode of the TRG specimens, as seen in Figure 9. There are two different types of failure modes which demonstrate the general failure modes of all the TRG specimens. For the TRG specimens without the BF addition, the poor bonding performance between the textile layer and the geopolymer matrix leads to the gradual peeling process of the fibre yarns that occurs out from the matrix, followed by the collapse of the matrix due to it reaching its maximum load-bearing capacity. It was found that although the geopolymer mortar without the BF addition used in this work had significantly higher mechanical strength than that in the previous publication [27], both types of mortar still induce the TRG specimens to have the same failure mode as the debonding phase within the matrix occurred. The textile reinforced specimens with the $\mathrm{BF}$ addition, on the contrary, result in a pure flexural failure without a debonding phase due to the slipping of the fibre yarn within the matrix. It can be said that the use of chopped basalt fibres in the production of the geopolymer mortar has markedly improved the rigidity of the matrix structure and has also promoted the cohesion

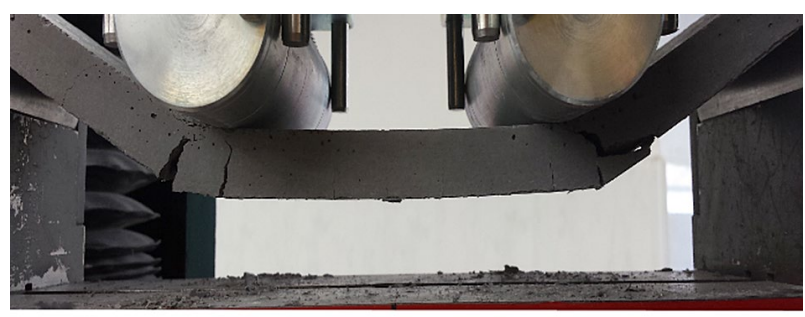

$7.5 \%$ addition of choped basalt fibre

Figure 9. The failure mode of the one textile layer reinforced specimens without and with the $7.5 \% \mathrm{BF}$. 
of the fibre yarns of the carbon textile in the matrix. This result confirms that adding the BF into geopolymer matrix positively impacts the failure mode of the TRG specimens, and the use of the one-layer textile reinforcement is not strong enough to peel off the mortar matrix.

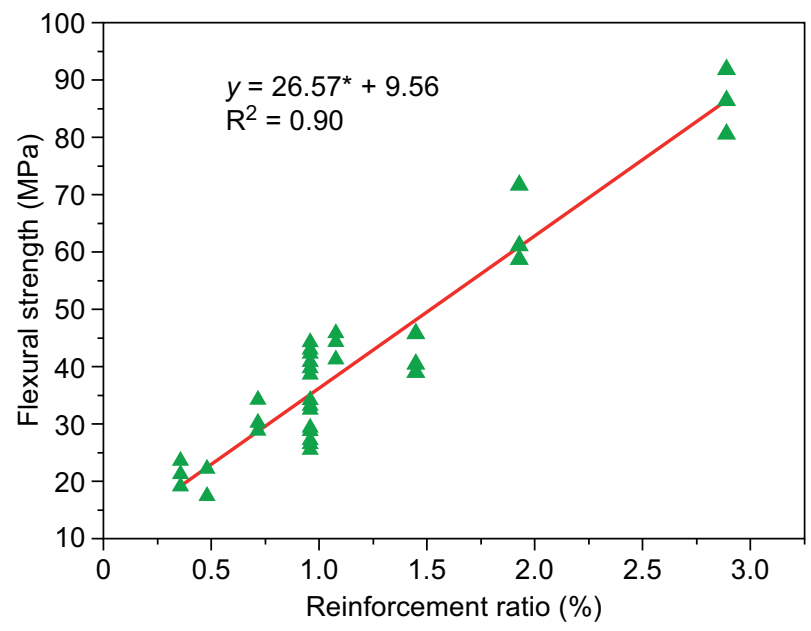

Figure 10. The correlation between the reinforcement ratio and the flexural strength.
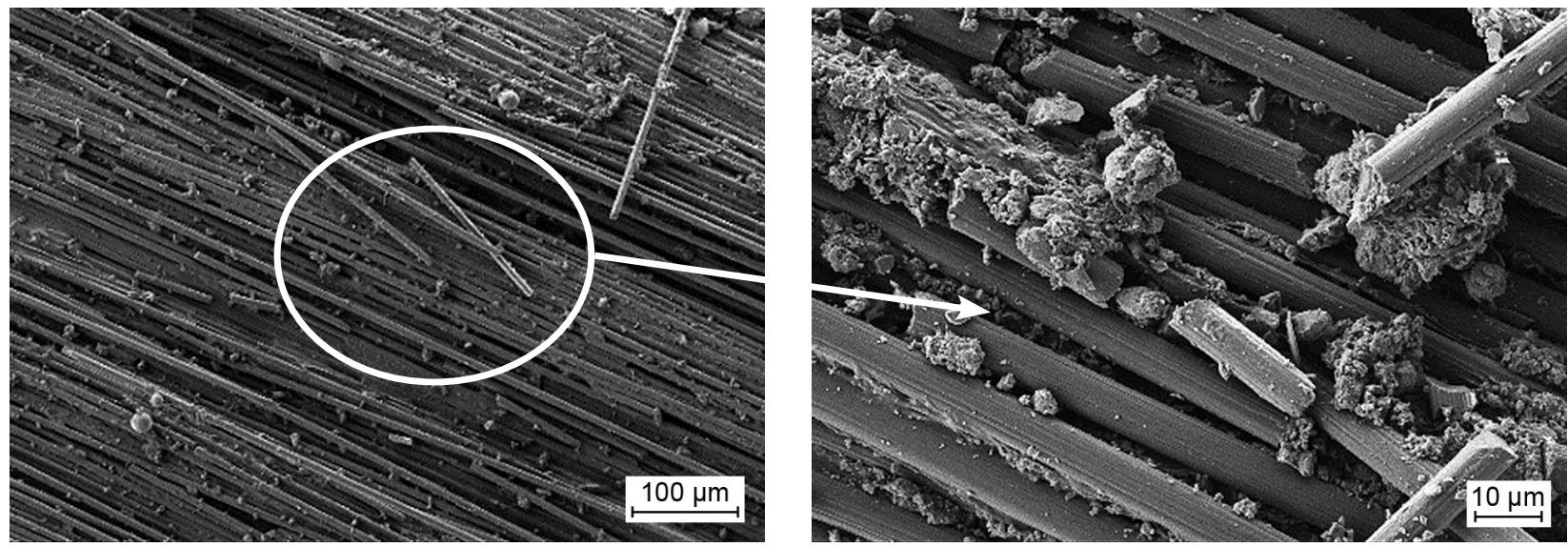

a) Carbon fibre yarn embedded in the geopolymer mortar without the BF addition
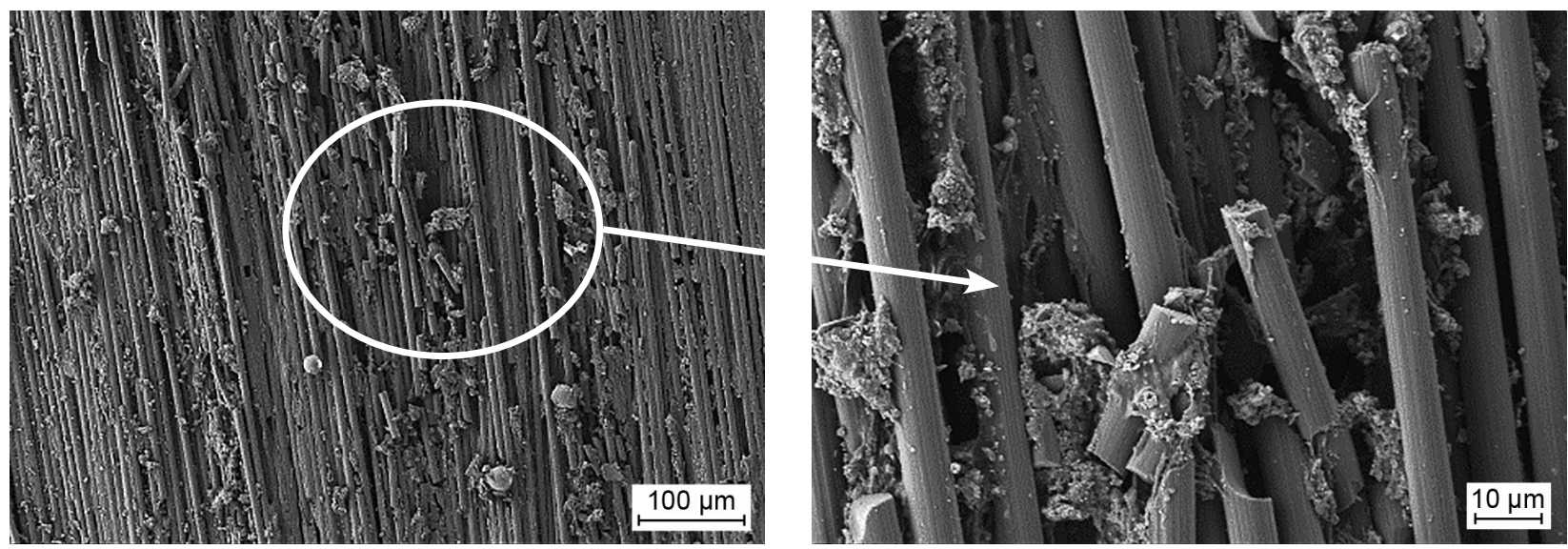

b) Carbon fibre yarn embedded in the geopolymer mortar with the addition of the $5 \% \mathrm{BF}$

Figure 11. The SEM images of the carbon fibre yarns extracted from the TRG specimens after the bending test. 


\section{CONCLUSIONS}

Based on the three types of carbon fibre fabric corresponding to the net size provided by Frisiverto s.r.o., Czech Republic, this paper experimentally investigated the flexural performance of the carbon textile reinforced geopolymer composite. The TRG specimens were produced and tested at the age of about 40 days after casting to evaluate the influence of the reinforcement ratio, carbon fabric type and various dosages of the $\mathrm{BF}$ on the mechanical properties of the TRG specimens. Based on the experimental results achieved, the following conclusions can be pointed out:

- With the increasing reinforcement ratio, the flexural strength of the TRG specimens were improved significantly especially with the TRG specimens reinforced with the $\mathrm{C}-10 \times 15$ textiles. In other words, the TRG specimens reinforced with the one-layer of the $\mathrm{C}-10 \times 15$ textile have an almost similar flexural strength achieved by those reinforced with the three layers of the $\mathrm{C}-21 \times 21$ textile and the $\mathrm{C}-34 \times 34$ textile.

- Using a high reinforcement ratio makes the $\mathrm{C}-10 \times 15$ composites achieve a high flexural strength, but they were catastrophically destroyed when compared to the remaining TRG specimens. The debonding and collapse phase took place simultaneously.

- Although the $\mathrm{C}-21 \times 21$ composites have a higher reinforcement ratio (considering the same reinforcing layer), they are unable to produce a higher flexural strength than those reinforced with the C-34×34 textiles.

- In contrast to the flexural strength, the $\mathrm{C}-21 \times 21 \mathrm{com}$ posites reinforced with the three layers (a reinforcement ratio of $1.45 \%$ ) achieved the highest flexural toughness while the $\mathrm{C}-10 \times 15$ composite reinforced with three layers $(2.89 \%)$ achieved the lowest one. The reason for this is that the higher elongation of the C- $21 \times 21$ textiles makes the TRG specimens obviously achieve greater ductility, which offsets their low flexural strength; as a result, the $\mathrm{C}-21 \times 21$ composites have a greater flexural toughness.

- The results obtained in this experiment suggest that the $\mathrm{C}-10 \times 15$ composites are suitable for high-strength and low-ductility applications while the composites reinforced with the remaining two types of carbon textile are useful for high-ductility applications.

- The chopped basalt fibres that were added into the geopolymer mortar were seen to significantly improve the mechanical properties and failure mode of the TRG specimens. The failure mode shifted from debonding at the matrix/fibre interface to a pure bending failure. The existence of the BF performed better in terms of cohesion of the carbon fibre yarn in the matrix due to the bridging effect and the results were sufficiently correlated to the mechanical strength of the TRG specimens. Moreover, the BF addition will help to reduce the overall shrinkage strains, thus decreasing the internal flaws in the matrix; as a result of improving the mechanical strength of the TRG specimens.

\section{Acknowledgements}

The results of the project "Development of textile products from non-combustible and recyclable materials", registration number CZ.01.1.02/0.0/0.0/1 6_084/0010282, were obtained through the financial support of the Ministry of Industry and Trade in the framework of the targeted support of the "Application III", the Operational Programme Enterprise and Innovations for Competitiveness.

\section{REFERENCES}

1. Davidovits J. (2017): Geopolymers: Ceramic-like inorganic polymers. Journal of Ceramic Science and Technology, 8, 335-350. doi: 10.4416/JCST2017-00038

2. Davidovits J. (1994). Properties of geopolymer cements. In: First international conference on alkaline cements and concretes (Vol. 1, pp. 131-149). Scientific Research Institute on Binders and Materials Kiev, Ukraine.

3. Meyer C. (2009): The greening of the concrete industry. Cement and Concrete Composites, 31, 601-605. doi: 10.1016/j.cemconcomp.2008.12.010

4. Verian K.P., Behnood A. (2018): Effects of deicers on the performance of concrete pavements containing aircooled blast furnace slag and supplementary cementitious materials. Cement and Concrete Composites, 90, 27-41. doi: 10.1016/j.cemconcomp.2018.03.009

5. Teh S.H., Wiedmann T., Castel A., de Burgh J. (2017): Hybrid life cycle assessment of greenhouse gas emissions from cement, concrete and geopolymer concrete in Australia. Journal of Cleaner Production, 152, 312-320. doi: 10.1016/j.jclepro.2017.03.122

6. Davidovits J. (2015): False Values on $\mathrm{CO}_{2}$ Emission for Geopolymer Cement/Concrete published in Scientific Papers, Technical Paper \#24. Geopolymer Inst. Libr., 1-9.

7. Sim J., Park C., Moon D.Y. (2005): Characteristics of basalt fiber as a strengthening material for concrete structures. Composites Part B: Engineering, 36, 504-512. doi: 10. 1016/j.compositesb.2005.02.002

8. Curbach M., Jesse F. (1999): High-Performance TextileReinforced Concrete. Structural Engineering International, 9, 289-291. doi: 10.2749/101686699780481745

9. Jabr A., El-Ragaby A., Ghrib F. (2017): Effect of the Fiber Type and Axial Stiffness of FRCM on the Flexural Strengthening of RC Beams. Fibers, 5, 2. doi: 10.3390/ fib5010002

10. Dey V., Zani G., Colombo M., Di Prisco M., Mobasher B. (2015): Flexural impact response of textile-reinforced aerated concrete sandwich panels. Materials \& Design, 86, 187-197. doi: 10.1016/j.matdes.2015.07.004

11. Colombo I.G., Colombo M., Di Prisco M. (2015): Bending behaviour of Textile Reinforced Concrete sandwich beams. Construction and Building Materials, 95, 675-685. doi: 10. 1016/j.conbuildmat.2015.07.169 
12. Kong K., Mesticou Z., Michel M., Si Larbi A., Junes A. (2017): Comparative characterization of the durability behaviour of textile-reinforced concrete (TRC) under tension and bending. Composite Structures, 179, 107-123. doi: 10. 1016/j.compstruct.2017.07.030

13. Williams Portal N., Flansbjer M., Zandi K., Wlasak L., Malaga K. (2017): Bending behaviour of novel Textile Reinforced Concrete-foamed concrete (TRC-FC) sandwich elements. Composite Structures, 177, 104-118. doi: 10. 1016/j.compstruct.2017.07.030

14. De Santis S., De Felice G. (2014): Tensile behaviour and durability of mortar-based strengthening systems with glass-aramid textiles. Key Engineering Materials, 624, 346-353. doi: 10.4028/www.scientific.net/KEM.624.346

15. Mechtcherine V. (2013): Novel cement-based composites for the strengthening and repair of concrete structures. Construction and Building Materials, 41, 365-373. doi: 10. 1016/j.conbuildmat.2012.11.117

16. Tamburini S., Natali M., Garbin E., Panizza M., Favaro M., Valluzzi M.R. (2017): Geopolymer matrix for fibre reinforced composites aimed at strengthening masonry structures. Construction and Building Materials, 141, 542-552. doi: 10.1016/j.conbuildmat.2017.03.017

17. Kurtz S., Balaguru P. (2001): Comparison of Inorganic and Organic Matrices for Strengthening of RC Beams with Carbon Sheets. Journal of Structural Engineering, 127, 35-42. doi: 10.1061/(ASCE)0733-9445(2001)127:1(35)

18. Khalid H.R., Ha S.K., Park S.M., Kim G.M., Lee H.K. (2015): Interfacial bond behavior of FRP fabrics bonded to fiber-reinforced geopolymer mortar. Composite Structures, 134, 353-368. doi: 10.1016/j.compstruct.2015.08.070

19. Menna C., Asprone D., Ferone C., Colangelo F., Balsamo A., Prota A. et al. (2013): Use of geopolymers for composite external reinforcement of RC members. Composites Part B: Engineering, 45, 1667-1676. doi: 10.1016/j.compositesb.2012.09.019

20. Zhang H., Hao X., Fan W. (2016): Experimental study on high temperature properties of carbon fiber sheets strengthened concrete cylinders using geopolymer as adhesive. Procedia Engineering, 135, 47-55. doi: 10.1016/j. proeng.2016.01.078

21. Katakalos K., Papakonstantinou C.G. (2009): Fatigue of Reinforced Concrete Beams Strengthened with Steel-Reinforced Inorganic Polymers. Journal of Composites for Construction, 13, 103-112. doi: 10.1061/(ASCE)10900268(2009)13:2(103)
22. Najm H., Secaras J., Balaguru P., Asce M. (2007): Compression Tests of Circular Timber Column Confined with Carbon Fibers Using Inorganic Matrix. Journal of Materials in Civil Engineering, 19, 198-204. doi: 10.1061/ (ASCE)0899-1561(2007)19:2(198)

23. Zhang H.Y., Lv H.R., Kodur V., Qi S.L. (2018): Comparative fire behavior of geopolymer and epoxy resin bonded fiber sheet strengthened RC beams. Engineering Structures, 155, 222-234. doi:10.1016/j.engstruct.2017.11.027

24. Vasconcelos E., Fernandes S., De Aguiar J.L.B., Pachecotorgal F. (2011): Concrete retrofitting using metakaolin geopolymer mortars and CFRP. Construction and Building Materials, 25,3213-3221. doi: 10.1016/j.conbuildmat.2011. 03.006

25. Fahim G., Mirza J., Ismail M., Ghoshal S.K., Abdulameer A. (2017): Geopolymer mortars as sustainable repair material: A comprehensive review. Renewable and Sustainable Energy Reviews, 80, 54-74. doi: 10.1016/j.rser.2017. 05.076

26. Le Chi H., Louda P., Le Van S., Volesky L., Kovacic V., Bakalova T. (2019): Composite Performance Evaluation of Basalt Textile-Reinforced Geopolymer Mortar. Fibers, 7, 63. doi: 10.3390/fib7070063

27. Le Chi H., Louda P., Periyasamy A., Bakalova T., Kovacic V. (2018): Flexural Behavior of Carbon Textile-Reinforced Geopolymer Composite Thin Plate. Fibers, 6, 87. doi: 10. 3390/fib6040087

28. BS EN (2005): Methods of Testing Cement - Part 1: Determination of Strength; European Committee for Standardization: Brussels, Belgium, 169, 36. doi: 10.1111/j. 1748-720X.1990.tb01123.x

29. D'Antino T., Papanicolaou C. (2017): Mechanical characterization of textile reinforced inorganic-matrix composites. Composites Part B: Engineering, 127, 78-91. doi: 10.1016/ j.compositesb.2017.02.034

30. Li V.C. (2008). Engineered Cementitious Composites (ECC ) - Material, Structural, and Durability Performance, in: Nawy, editor. Concrete Construction Engineering Handbook. CRC Press.

31. Branston J., Das S., Kenno S.Y., Taylor C. (2016): Influence of basalt fibres on free and restrained plastic shrinkage. Cement and Concrete Composites, 74, 182-190. doi: 10. 1016/j.cemconcomp.2016.10.004 